This item was submitted to Loughborough's Research Repository by the author.

Items in Figshare are protected by copyright, with all rights reserved, unless otherwise indicated.

\title{
Mode identification in impact-induced high-frequency vehicular driveline vibrations using an elasto-multi-body dynamics approach
}

PLEASE CITE THE PUBLISHED VERSION

PUBLISHER

Professional Engineering Publishing / @ IMECHE

VERSION

VoR (Version of Record)

\section{LICENCE}

CC BY-NC-ND 4.0

\section{REPOSITORY RECORD}

Theodossiades, Stephanos, M. Gnanakumarr, Homer Rahnejat, and M.T. Menday. 2019. "Mode Identification in Impact-induced High-frequency Vehicular Driveline Vibrations Using an Elasto-multi-body Dynamics Approach". figshare. https://hdl.handle.net/2134/4798. 
This item was submitted to Loughborough's Institutional Repository (https://dspace.lboro.ac.uk/) by the author and is made available under the following Creative Commons Licence conditions.

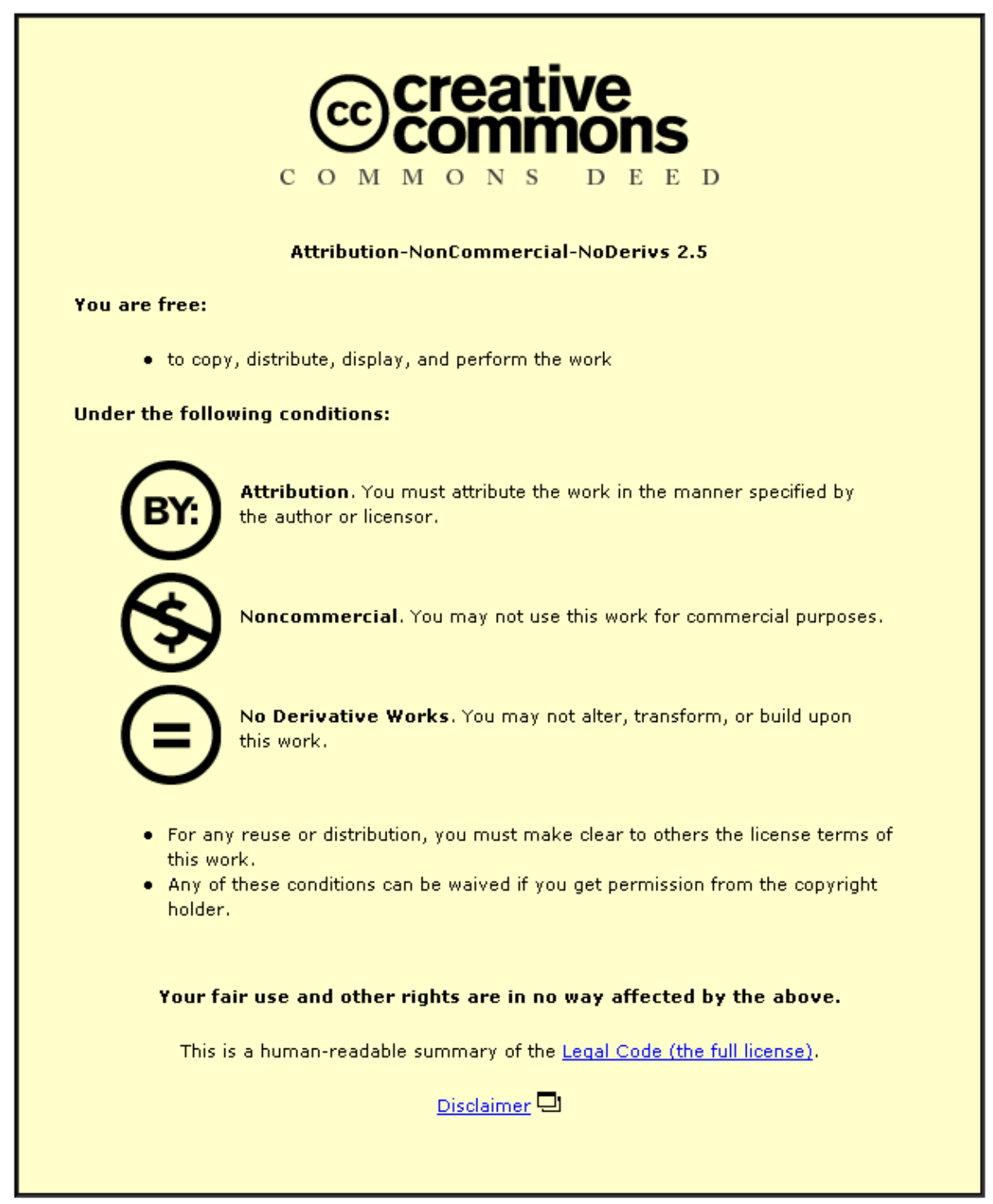

For the full text of this licence, please go to: http://creativecommons.org/licenses/by-nc-nd/2.5/ 


\title{
Mode identification in impact-induced high-frequency vehicular driveline vibrations using an elasto-multi-body dynamics approach
}

\author{
S Theodossiades ${ }^{1}, \mathbf{M}$ Gnanakumarr ${ }^{1}, \mathbf{H}_{\text {Rahnejat }}{ }^{1 *}$ and $\mathbf{M}$ Menday $^{2}$ \\ ${ }^{1}$ Wolfson School of Mechanical and Manufacturing Engineering, Loughborough University, Loughborough, UK \\ ${ }^{2}$ Ford Engineering Research Centre, Dunton, Essex, UK
}

\begin{abstract}
The paper describes a noise, vibration and harshness (NVH) phenomenon caused by impact of meshing gear teeth pairs, resulting in structural wave propagation and elastoacoustic coupling in the driveline system, referred to in industry as clonk. The numerical investigation combines multi-body dynamics analysis with flexible body oscillation behaviour predicted by finite element analysis (FEA) techniques. Particular attention is paid to local non-linearities such as the varying stiffness of meshing gear teeth and their normal backlash. The spectrum of vibration of lightly damped hollow driveshaft tubes shows good conformity with experimental results.
\end{abstract}

Keywords: elasto-multi-body approach, clonk, impact, backlash, driveline modes

\section{NOTATION}

$C_{k} \quad$ constraint function

$D \quad$ damping energy dissipation function

$F_{\xi_{j}} \quad$ generalised applied forces projected on $\xi$

$k(t) \quad$ gear teeth pair contact stiffness

$K_{\mathrm{i}} \quad$ ball-to-inner race contact stiffness

$K_{\mathrm{o}} \quad$ ball-to-outer race contact stiffness

$K_{\mathrm{p}} \quad$ effective point contact coefficient of proportionality

$L \quad$ Lagrangian

$m \quad$ number of independent coordinates

$n \quad$ number of constraints

$n_{1} \quad$ number of teeth on the pinion

$n_{2} \quad$ Number of teeth on the driven gear

$q \quad$ elastic nodal coordinates

$R_{1,2} \quad$ pitch radii of the pinion and driven gear respectively

$T \quad$ kinetic energy

$\boldsymbol{u}$ linear nodal deformation vector

$V \quad$ potential energy

$W \quad$ ball-race contact force

$x, y, z \quad$ translational degrees of freedom
$\mathbf{Z}$

damping ratio matrix

The MS was received on 29 July 2003 and was accepted after revision for publication on 16 February 2004.

*Corresponding author: Wolfson School of Mechanical and Manufacturing Engineering, Loughborough University, Loughborough, Leicestershire LE11 $3 T U$, UK.

$\alpha, \beta, \gamma$
$\delta$
$\lambda_{\kappa}$
$\boldsymbol{\xi}_{j}$
$\boldsymbol{\phi}$
$\boldsymbol{\Phi}_{\mathrm{IC}}$
$\boldsymbol{\Phi}_{\mathrm{IN}}$
$\psi, \theta, \varphi$
$\omega_{\mathbf{M}}$
$\omega_{1}$
$\omega_{2}$

driveline inclination angles

ball-inner and outer race effective

Hertzian contact deformation

Lagrange multipliers

generalized coordinates

deformation shape function

physical displacements of the interior degrees of freedom in the constraint modes

physical displacements of the interior degrees of freedom in the normal modes

Euler angles

gear meshing frequency

angular velocity of the pinion

angular velocity of the driven gear

\section{INTRODUCTION}

The presence of various lash zones in vehicular drivelines (transmission and differential gears, spline joints, etc.) amplifies the appearance and effects of noise, vibration and harshness $(\mathrm{NVH})$ phenomena on the system. A typical driveline NVH spectrum contains the contribution of a significant number of vibration components, ranging from a few $\mathrm{Hz}$ to several $\mathrm{kHz}$, depending on the elasticity of the particular components, their natural modal density and the characteristics of the transmitting torque through the system. These contributions have usually strong interaction effects. Among the most interactive phenomena are three of the major 
concerns at extremes of the spectrum, namely clonk, shuffle and shunt. Clonk is a short-duration, audible, high-frequency, elastoacoustic phenomenon that occurs as a load reversal in the presence of lashes in the driveline $(300-5000 \mathrm{~Hz})[\mathbf{1}-\mathbf{4}]$. This load reversal is often induced by vibroimpact interactions in lash through a low-frequency coupled torsional/ longitudinal rigid body motion of the powertrain system, known as shuffle/Shunt [5-8]. Clonk may be heard on the first cycle of the shuffle/shunt response [9-12]. Possible causes of shuffle, shunt and clonk are as follows:

(a) rapid application of throttle from coast to drive condition or rapid release of throttle from drive to coast condition, especially at low gear and at low road speeds;

(b) rapid engagement/disengagement of the clutch;

(c) sudden loading that causes a low-frequency fore and aft motion of the vehicle.

In all cases, the rise rate of the transmitted torque pulse has a steep gradient and is referred to as jerk. Its short duration acts as an impulse that excites a large number of structural modes of the lightly damped driveline system. The shorter this duration, the greater is the number of modes that are excited. The highfrequency content of the modal response propagates to the passenger cabin as airborne noise. In particular, components such as the driveshaft pieces and the transmission bell housing are effective noise radiators, since the advances in material science and computational mechanics, in addition to continual efforts to achieve lower production costs, have affected their design by a significant reduction in their thickness. Their vibration response and, hence, the externally radiated sound power are thought to be mainly determined by the possible coincidence or coupling of the higher-order acoustic modes of the cavity and the resonant structural modes of the walls $[\mathbf{1 3}, \mathbf{1 4}]$.

\section{VEHICLE DRIVELINE MODEL}

The determination of conditions that lead to vibroimpact excitation of the driveline, induce structural wave propagation and cause coupling between the acoustic modes of the cavity and the higher structural modes of the lightly damped thin-walled components is of major importance for the investigation of the clonk phenomenon. Consequently, detailed and accurate modelling of the drivetrain system is required. Multiphysics problems of this type must be investigated through a combined study of large-displacement inertial dynamics, small-amplitude structural elastodynamics and acoustic wave propagation. In the present paper, the first two approaches have been introduced and examined in conjunction with experimental verification.

A multi-body dynamic model (see Fig. 1) based upon constrained Lagrangian dynamics forms the basis for the representation of the drivetrain system. The commercially available software ADAMS [15] has been employed for this purpose. Component flexibility, particularly for the high modal density radiated noise structures, has also been included through the use of the finite element technique and the component mode synthesis method in order to limit the domain of the eigenvalue problem for computational convenience. The same model may be employed to study the radiated noise from the mechanical parts of interest using finite elements (which can become a time consuming approach) or by the boundary element method. The finite element approach is taken with the use of the commercially available software NASTRAN [16], while the Craig-Brampton method has been used to reduce the total number of elastic degrees of freedom.

The multi-body model comprises all the component parts of the powertrain system, starting from the transmission input shaft up to and including the rear axle half-shafts, through the use of Parasolid computer aided design (CAD) files permitting the exact representation of their physical properties. The mass and inertial properties of every rigid body component, the constraints introduced by the connecting idealized joints, the compliances-restraints of the model and the applied external forces are described in Tables 1 to 4, respectively. The physical properties obtained by finite

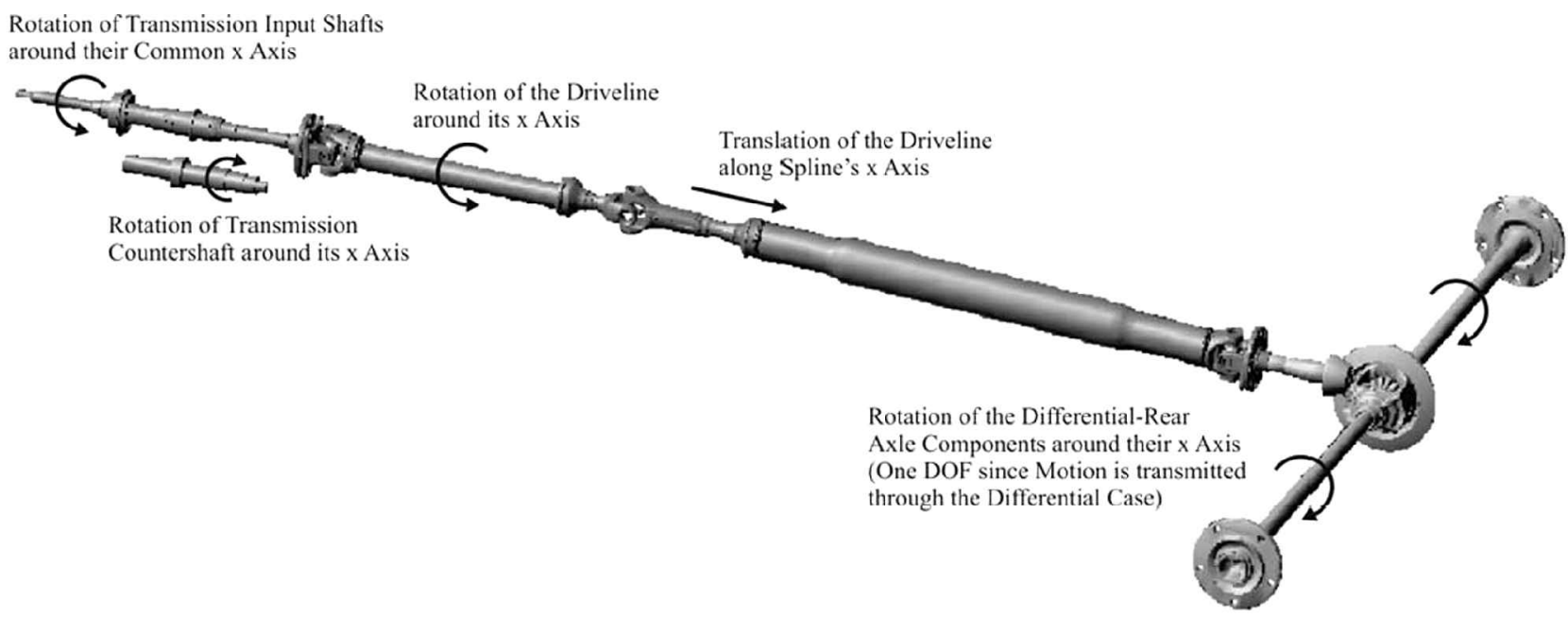

Fig. 1 Multi-body model of the drivetrain mechanical system 
Table 1 Mass and inertia properties of the vehicle drivetrain model components

\begin{tabular}{|c|c|c|c|c|c|}
\hline \multirow[b]{2}{*}{ Number } & \multirow[b]{2}{*}{ Part name/description } & \multirow[b]{2}{*}{ Mass (kg) } & \multicolumn{3}{|c|}{ Moments of inertia $\left(\mathrm{kg} \mathrm{m}^{2}\right)$} \\
\hline & & & $I_{x x}$ & $I_{y y}$ & $I_{z z}$ \\
\hline 1 & Transmission input shaft & 1.82 & $9.16 \times 10^{-4}$ & $7.59 \times 10^{-3}$ & $7.59 \times 10^{-3}$ \\
\hline 2 & Transmission main shaft & 1.79 & $4.39 \times 10^{-4}$ & $3.84 \times 10^{-3}$ & $3.84 \times 10^{-3}$ \\
\hline 3 & Transmission countershaft & 3.15 & $8.11 \times 10^{-4}$ & $1.85 \times 10^{-2}$ & $1.85 \times 10^{-2}$ \\
\hline 4 & Transmission output shaft & 1.83 & $4.11 \times 10^{-4}$ & $8.41 \times 10^{-3}$ & $8.41 \times 10^{-3}$ \\
\hline 5 & Transmission output flange & 1.24 & $2.34 \times 10^{-3}$ & $1.25 \times 10^{-3}$ & $1.22 \times 10^{-3}$ \\
\hline 6 & Output flange yoke & 0.82 & $1.32 \times 10^{-3}$ & $1.05 \times 10^{-3}$ & $5.77 \times 10^{-4}$ \\
\hline 7 & First spider & 0.35 & $1.87 \times 10^{-4}$ & $1.04 \times 10^{-4}$ & $1.04 \times 10^{-4}$ \\
\hline 8 & First driveshaft yoke & 0.80 & $9.42 \times 10^{-4}$ & $8.62 \times 10^{-4}$ & $4.57 \times 10^{-4}$ \\
\hline 9 & First driveshaft tube & 0.88 & $5.68 \times 10^{-4}$ & $5.6 \times 10^{-2}$ & $5.6 \times 10^{-2}$ \\
\hline 10 & First driveshaft end & 0.97 & $5.27 \times 10^{-4}$ & $9.13 \times 10^{-4}$ & $9.63 \times 10^{-4}$ \\
\hline 11 & Yoke & 0.85 & $7.58 \times 10^{-4}$ & $5.05 \times 10^{-4}$ & $1.00 \times 10^{-3}$ \\
\hline 12 & Female slip spline & 1.16 & $8.72 \times 10^{-4}$ & $3.37 \times 10^{-3}$ & $3.00 \times 10^{-3}$ \\
\hline 13 & Male slip spline & 1.76 & $6.79 \times 10^{-4}$ & $6.69 \times 10^{-3}$ & $6.73 \times 10^{-3}$ \\
\hline 14 & Second driveshaft tube & 3.26 & $5.95 \times 10^{-3}$ & 0.98 & 0.98 \\
\hline 15 & Second driveshaft end & 0.80 & $9.42 \times 10^{-4}$ & $8.62 \times 10^{-4}$ & $4.57 \times 10^{-4}$ \\
\hline 16 & Second spider & 0.35 & $1.87 \times 10^{-4}$ & $1.04 \times 10^{-4}$ & $1.04 \times 10^{-4}$ \\
\hline 17 & Axle yoke & 0.82 & $1.32 \times 10^{-3}$ & $1.05 \times 10^{-3}$ & $5.77 \times 10^{-4}$ \\
\hline 18 & Axle flange & 1.24 & $2.34 \times 10^{-3}$ & $1.25 \times 10^{-3}$ & $1.22 \times 10^{-3}$ \\
\hline 19 & Axle pinion & 2.63 & $1.11 \times 10^{-3}$ & $9.03 \times 10^{-3}$ & $9.03 \times 10^{-3}$ \\
\hline 20 & Crown wheel gear & 4.80 & $2.00 \times 10^{-2}$ & $3.93 \times 10^{-2}$ & $2.00 \times 10^{-2}$ \\
\hline 21 & Axle differential case & 5.62 & $1.81 \times 10^{-2}$ & $1.90 \times 10^{-2}$ & $2.14 \times 10^{-2}$ \\
\hline 22 & RH side gear (1) & 0.57 & $2.58 \times 10^{-4}$ & $4.33 \times 10^{-4}$ & $2.58 \times 10^{-4}$ \\
\hline 23 & LH side gear (3) & 0.57 & $2.58 \times 10^{-4}$ & $4.33 \times 10^{-4}$ & $2.58 \times 10^{-4}$ \\
\hline 24 & Front side gear (4) & 0.25 & $1.03 \times 10^{-4}$ & $5.89 \times 10^{-5}$ & $1.03 \times 10^{-4}$ \\
\hline 25 & Back side gear (2) & 0.25 & $1.03 \times 10^{-4}$ & $5.89 \times 10^{-5}$ & $1.03 \times 10^{-4}$ \\
\hline 26 & Side gear shaft & 0.36 & $2.25 \times 10^{-5}$ & $4.72 \times 10^{-4}$ & $4.72 \times 10^{-4}$ \\
\hline 27 & Left half-shaft & 11.44 & 0.89 & $1.49 \times 10^{-2}$ & 0.89 \\
\hline 28 & Right half-shaft & 11.44 & 0.89 & $1.49 \times 10^{-2}$ & 0.89 \\
\hline 29 & Ground & - & - & - & - \\
\hline
\end{tabular}

Table 2 Constraints between connecting components in the multi-body drivetrain model

\begin{tabular}{|c|c|c|c|c|}
\hline Number & Part I & Part J & Constraint type & $\begin{array}{l}\text { Number } \\
\text { of constraints }\end{array}$ \\
\hline 1 & Transmission input shaft & Transmission main shaft & Fixed & 6 \\
\hline 2 & Transmission main shaft & Ground & Revolute & 5 \\
\hline 3 & Transmission countershaft & Ground & Revolute & 5 \\
\hline 4 & Transmission output shaft & Ground & Revolute & 5 \\
\hline 5 & Transmission output shaft & Transmission output flange & Fixed & 6 \\
\hline 6 & Transmission output flange & Output flange yoke & Fixed & 6 \\
\hline 7 & Output flange yoke & First spider & Revolute & 5 \\
\hline 8 & First spider & First driveshaft yoke & Revolute & 5 \\
\hline 9 & First driveshaft yoke & First driveshaft tube & Fixed & 6 \\
\hline 10 & First driveshaft tube & First driveshaft end & Fixed & 6 \\
\hline 11 & First driveshaft end & Yoke & Fixed & 6 \\
\hline 12 & Yoke & Female slip spline & Hooke & 4 \\
\hline 13 & Female slip spline & Male slip spline & Cylindrical & 4 \\
\hline 14 & Male slip spline & Second driveshaft tube & Fixed & 6 \\
\hline 15 & Second driveshaft tube & Second driveshaft end & Fixed & 6 \\
\hline 16 & Second driveshaft end & Second spider & Revolute & 5 \\
\hline 17 & Second spider & Axle yoke & Revolute & 5 \\
\hline 18 & Axle yoke & Axle flange & Fixed & 6 \\
\hline 19 & Axle flange & Ground & Revolute & 5 \\
\hline 20 & Axle flange & Axle pinion & Fixed & 6 \\
\hline 21 & Axle pinion & Crown wheel gear & Coupler & 1 \\
\hline 22 & Crown wheel gear & Axle differential case & Fixed & 6 \\
\hline 23 & Crown wheel gear & Ground & Revolute & 5 \\
\hline 24 & Axle differential case & RH side gear (1) & Fixed & 6 \\
\hline 25 & Axle differential case & LH side gear (3) & Fixed & 6 \\
\hline 26 & Axle differential case & Side gear shaft & Fixed & 6 \\
\hline 27 & Side gear shaft & Front side gear (4) & Fixed & 6 \\
\hline 28 & Side gear shaft & Back side gear (2) & Fixed & 6 \\
\hline 29 & RH side gear (1) & RH half-shaft & Fixed & 6 \\
\hline 30 & LH side gear (3) & LH half-shaft & Fixed & 6 \\
\hline
\end{tabular}


Table 3 Restraints and compliances in the driveline model

\begin{tabular}{lll}
\hline Number & Parts/areas of application & Characteristics \\
\hline 1 & First driveshaft tube & Superelement, 82 modes \\
2 & Second driveshaft tube & Superelement, 312 modes \\
3 & Total normal backlash, & Experimental data, 63 $\mu \mathrm{m}$ \\
& fourth gear set & \\
4 & Total normal backlash, & Experimental data, 75 $\mu \mathrm{m}$ \\
& second gear set & \\
5 & Transmission, first driveshaft & Manufacturing data, \\
& angle $\alpha$ (see Fig. 2) & Table 5 \\
6 & First-second driveshaft angle & Manufacturing data, \\
& $\beta$ (see Fig. 2) & Table 5 \\
7 & Second driveshaft, axle & Manufacturing data, \\
& pinion angle $\varphi$ (see Fig. 2) & Table 5 \\
8 & Torsional spline stiffness & $1.1 \times 10^{6} \mathrm{~N} \mathrm{~m} / \mathrm{rad}$ \\
\hline
\end{tabular}

element analysis (FEA) correspond to elastic solids for which a mass value is not considered in Table 1 .

The total number of degrees of freedom (DOF) of the multi-body drivetrain model is obtained using the GrueblerKutzbach expression as

$$
\begin{aligned}
\text { Number of DOF }= & \text { flexible body modes }+6 \\
& \times(\text { number of rigid parts }-1) \\
& -\Sigma(\text { constraints }) \\
= & (82+312)+6 \times(27-1)-163 \\
= & 388
\end{aligned}
$$

Hence, the drivetrain model has 388 degrees of freedom. In the simpler case, where flexibility is not included in the system, the same expression becomes

$$
\begin{aligned}
& \text { Number of DOF } \\
& \qquad 6 \times(\text { number of rigid parts }-1)-\Sigma \text { (constraints) } \\
& =6 \times(29-1)-163=5
\end{aligned}
$$

Thus, the rigid drivetrain model has five degrees of freedom, which are shown in Fig. 1.

\section{METHOD OF FORMULATION AND SOLUTION}

The governing equations of motion for a rigid and flexible body are derived from Lagrange's equations

$$
\frac{\mathrm{d}}{\mathrm{d} t}\left(\frac{\partial L}{\partial \dot{\boldsymbol{\xi}}_{j}}\right)-\frac{\partial L}{\partial \boldsymbol{\xi}_{j}}+\frac{\partial D}{\partial \dot{\boldsymbol{\xi}}_{j}}-F_{\xi_{j}}+\sum_{k=1}^{n} \lambda_{k} \frac{\partial C_{k}}{\partial \boldsymbol{\xi}_{j}}=0
$$

where $\left\{\boldsymbol{\xi}_{j}\right\}_{j=1 \rightarrow 6}=\{x, y, z, \psi, \theta, \varphi\}^{\mathrm{T}}$ for the rigid body degrees of freedom, $\left\{\boldsymbol{\xi}_{j}\right\}_{j=1 \rightarrow 6+m}=\{x, y, z, \psi, \theta, \varphi, q\}^{\mathrm{T}}$ for the flexible bodies ( $q$ represents the modal coordinates and $m$ their total number), $L=T-V$ is the Lagrangian, i.e. the difference between kinetic and potential energies, and $D=\frac{1}{2} \dot{\boldsymbol{q}}^{\mathrm{T}} \mathbf{Z} \dot{\boldsymbol{q}}$.

The $n$ constraint functions for the different joints in the driveline model are represented by a combination of holonomic and non-holonomic functions as

$$
\left[\begin{array}{c}
C_{k} \\
\dot{\xi}_{j} \frac{\partial C_{k}}{\partial \xi_{j}}
\end{array}\right]=0, \quad j=1 \longrightarrow 6 \text { or } 1 \longrightarrow 6+m, k=1 \longrightarrow n
$$

Therefore, the multi-body model of the mechanical system is a constrained non-linear dynamics model incorporating the elastic behaviour of the driveshaft tubes.

\subsection{Component mode synthesis and superelement creation}

The introduction of FEA techniques for the detailed investigation of the behaviour of several parts of the driveline has been considered as necessary because it achieves two desirable goals:

1. It increases the reliability and accuracy of the multi-body model.

2. The realistic loads and initial conditions that are required for a noise radiation analysis may be obtained in a natural

Table 4 Internal and external applied forces

\begin{tabular}{llll}
\hline Number & Type & Position & Magnitude \\
\hline 1 & Ramp torque & Transmission input shaft & According to driver's behaviour (80-135 ms) \\
2 & Fourth gear set torque & Gear meshing cycle & Hertzian, bending \\
3 & Second gear set torque & Gear meshing cycle & Hertzian, bending \\
4 & Bearing force & Central bearing & Hertzian \\
\hline
\end{tabular}

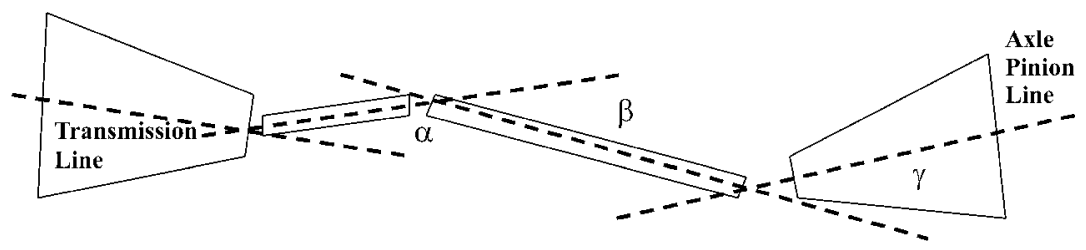

Fig. 2 Side view of driveline angles 
Table 5 Driveline angles data

\begin{tabular}{llll}
\hline Chassis & $\begin{array}{l}\alpha \\
\text { (negative } \\
\text { as shown) }\end{array}$ & $\begin{array}{l}\beta \\
\text { (positive } \\
\text { as shown) }\end{array}$ & $\begin{array}{l}\gamma \\
\text { (negative } \\
\text { as shown) }\end{array}$ \\
\hline $\begin{array}{c}\text { Unladen } \\
\text { vehicle }\end{array}$ & $1^{\circ} 35^{\prime}$ negative & $2^{\circ} 57^{\prime}$ positive & $2^{\circ} 55^{\prime}$ negative \\
$\begin{array}{c}\text { Half-laden } \\
\text { vehicle }\end{array}$ & $1^{\circ} 35^{\prime}$ negative & $1^{\circ} 9^{\prime}$ positive & $50^{\prime}$ negative \\
$\begin{array}{c}\text { Fully laden } \\
\text { vehicle }\end{array}$ & $1^{\circ} 35^{\prime}$ negative & $41^{\prime}$ negative & $43^{\prime}$ negative \\
\hline
\end{tabular}

way by incorporating an FEA model of a specific component in the mechanical system and simulating the in-service events of interest.

The driveshaft pieces (first and second tubes) are major components of the driveline that have significant flexural behaviour owing to their small wall thickness compared with the other parts that present a rather rigid behaviour. By incorporating FEA models instead of rigid bodies for the representation of these components, it is also feasible to determine the principal stresses that are generated during the simulation exercise. Furthermore, the initial and boundary conditions (displacements, velocities, loads, etc.) that are required for an acoustic analysis of the driveshafts can be extracted, enabling determination of sound pressure fields in the exterior domain.

The most important assumption behind this procedure is the consideration of small, linear body deformations relative to a local frame of reference, while this local frame of reference undergoes large, non-linear motion with respect to a fixed global frame of reference. The discretization of a component into a finite element model represents the infinite number of degrees of freedom with a finite but very large number of degrees of freedom. The linear deformations of the nodes of this finite element mode, $\boldsymbol{u}$, can be approximated as a linear combination of a smaller number of shape vectors (or mode shapes), $\boldsymbol{\phi}$,

$$
\boldsymbol{u}=\sum_{i=1}^{m} \boldsymbol{\phi}_{i} \boldsymbol{q}_{i}
$$

where $m$ is the number of mode shapes. The scale factors of amplitudes, $\boldsymbol{q}$, are the modal coordinates.

The main concept of modal superposition is that the behaviour of a component with a very large number of nodal DOF in a predetermined frequency area can be captured with a much smaller number of modal degrees of freedom. Thus, the finite element modes can be rewritten in matrix form as

$$
\boldsymbol{u}=\boldsymbol{\Phi} \boldsymbol{q}
$$

where $\boldsymbol{q}$ is the vector of modal coordinates and the modes $\boldsymbol{\phi}_{i}$ are included in the columns of the modal matrix $\boldsymbol{\Phi}$. This matrix is the transformation from the small set of modal coordinates, $\boldsymbol{q}$, to the larger set of physical coordinates, $\boldsymbol{u}$.
The determination of the modal matrix $\mathbf{M}$ can be achieved by the Craig-Brampton reduction method [17], which is one of the most general methods for component mode synthesis. A summary of this method is described below:

1. A set of boundary degrees of freedom, $\boldsymbol{u}_{\mathrm{B}}$, is defined, which is not to be subject to modal superposition and is preserved exactly in the modal basis.

2. A set of interior degrees of freedom, $\boldsymbol{u}_{\mathrm{I}}$, is defined.

Additionally, two sets of mode shapes are defined as follows:

1. The constraint modes, $\boldsymbol{q}_{\mathrm{C}}$, are static shapes that are obtained by giving each of the boundary degrees of freedom a unit displacement while holding all other boundary degrees of freedom fixed. There is a one-toone correspondence between the modal coordinates of the constraint modes and the displacement in the corresponding boundary degrees of freedom, $\boldsymbol{q}_{\mathrm{C}}=\boldsymbol{u}_{\mathrm{B}}$.

2. The fixed boundary normal modes, $\boldsymbol{q}_{\mathrm{N}}$, which are obtained by fixing the boundary degrees of freedom and computing a solution of the eigenvalue problem. These modes define the modal expansion of the interior degrees of freedom. The quality of this expansion is proportional to the total number of modes.

According to the above, the relationship between the physical degrees of freedom, the Craig-Brampton modes and their modal coordinates is expressed as

$$
\boldsymbol{u}=\left(\begin{array}{c}
\boldsymbol{u}_{\mathrm{B}} \\
\boldsymbol{u}_{\mathrm{I}}
\end{array}\right)=\left(\begin{array}{cc}
\mathbf{I} & \mathbf{0} \\
\boldsymbol{\Phi}_{\mathrm{IC}} & \boldsymbol{\Phi}_{\mathrm{IN}}
\end{array}\right)\left(\begin{array}{c}
\boldsymbol{q}_{\mathrm{C}} \\
\boldsymbol{q}_{\mathrm{N}}
\end{array}\right)
$$

where $\mathbf{I}$ and $\mathbf{0}$ are unity and zero matrices respectively.

The generalized stiffness and mass matrices are obtained through the following transformations

$$
\begin{aligned}
& \hat{\mathbf{M}}=\boldsymbol{\Phi}^{\mathrm{T}} \mathbf{M} \boldsymbol{\Phi}=\left(\begin{array}{cc}
\hat{\mathbf{M}}_{\mathrm{CC}} & \mathbf{0} \\
\mathbf{0} & \hat{\mathbf{M}}_{\mathrm{NN}}
\end{array}\right), \\
& \hat{\mathbf{K}}=\boldsymbol{\Phi}^{\mathrm{T}} \mathbf{K} \boldsymbol{\Phi}=\left(\begin{array}{cc}
\hat{\mathbf{K}}_{\mathrm{CC}} & \mathbf{0} \\
\mathbf{0} & \hat{\mathbf{K}}_{\mathrm{NN}}
\end{array}\right)
\end{aligned}
$$

where, $\hat{\mathbf{M}}_{\mathrm{NN}}$ and $\hat{\mathbf{K}}_{\mathrm{NN}}$ are diagonal matrices and $\hat{\mathbf{K}}$ is a block diagonal matrix.

Next, a mode shape orthonormalization is applied, which resolves the following problems:

1. The six rigid body modes are addressed and can now be disabled.

2. All modes now have an associated natural frequency, which helps to classify them physically and simulate non-linear systems with an unknown frequency content. 
By solving the eigenvalue problem

$$
\hat{\mathbf{K}} \boldsymbol{q}=\lambda \hat{\mathbf{M}} \boldsymbol{q}
$$

the obtained eigenvectors are arranged in a transformation matrix $\mathbf{N}$ that transforms the Craig-Brampton modal basis to an equivalent, orthogonal basis with modal coordinates $\boldsymbol{q}^{*}$, where

$$
\mathbf{N} q^{*}=\boldsymbol{q}
$$

Thus, the effect on the superposition formula is

$$
\boldsymbol{u}=\sum_{i=1}^{m} \boldsymbol{\phi}_{i} \boldsymbol{q}_{i}=\sum_{i=1}^{m} \boldsymbol{\phi}_{i} \mathbf{N} \boldsymbol{q}^{*}=\sum_{i=1}^{m} \boldsymbol{\phi}_{i}^{*} \boldsymbol{q}^{*}
$$

where $\boldsymbol{\phi}_{i}^{*}$ are the orthogonal Craig-Brampton modes.

Four-noded shell elements with prespecified thickness $(1.65 \mathrm{~mm})$ have been used for the tube walls in the superelement creation instead of solid elements, since the ratio of tube radii to tube thickness is very high $(>20)$. The number of elements and their size across the shaft length and on the perimeter has been kept large enough for the higher modes with complicated shapes to be captured efficiently. Clampedclamped boundary conditions have been applied to the tube edges to represent the actual assembly conditions in the vehicular drivetrain system. This has been achieved by using appropriate connections in the tube edges so that a central master node (at the edge centre) is rigidly attached to many slave circumferential nodes (on the perimeter) via rigid boundary elements. This type of connection creates a localized stiffness in the model. Since the master node degrees of freedom are independent, this node can be promoted to an attachment point and used to connect the flexible body to the neighbouring rigid bodies of the multi-body model.

A sufficient number of structural modes have been kept in the superelement creation to obtain accurate results in the

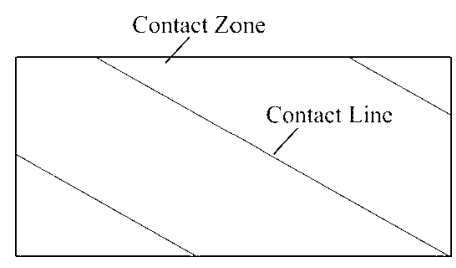

Fig. 3 Zone of contact and contact elements (three teeth pairs in contact)

specified frequency area where clonk usually occurs (300$5000 \mathrm{~Hz}$ ). There is no exact rule regarding the number of modes that should be kept in the superelement model, although a general rule of thumb is that a number of modes covering at least twice the desired frequency area should be kept. The geometric properties of every tube determine its modal density in this spectrum area (its upper limit has been determined at $12000 \mathrm{~Hz}$ in this analysis). Consequently, each tube superelement includes a variety of modes, starting from low-frequency bending behaviour and leading on to complicated flexural shapes that are combined by the superposition of bending-axial and high-frequency torsional modes.

\subsection{Gear meshing cycle forces}

The analytical representation and calculation of the developing transmission gear forces between the engaged teeth pair(s) during the meshing cycle is a critical task, because their inclusion contributes significantly to the successful simulation of the impact conditions and they are a significant source of non-linearity in the system. The special geometric characteristics of the helical gear teeth affect the dynamics and vibrational behaviour of the mechanical system in a significant way. In the presence of gear backlash, which is either introduced intentionally at the design stages or caused by manufacturing errors and wear, the equations

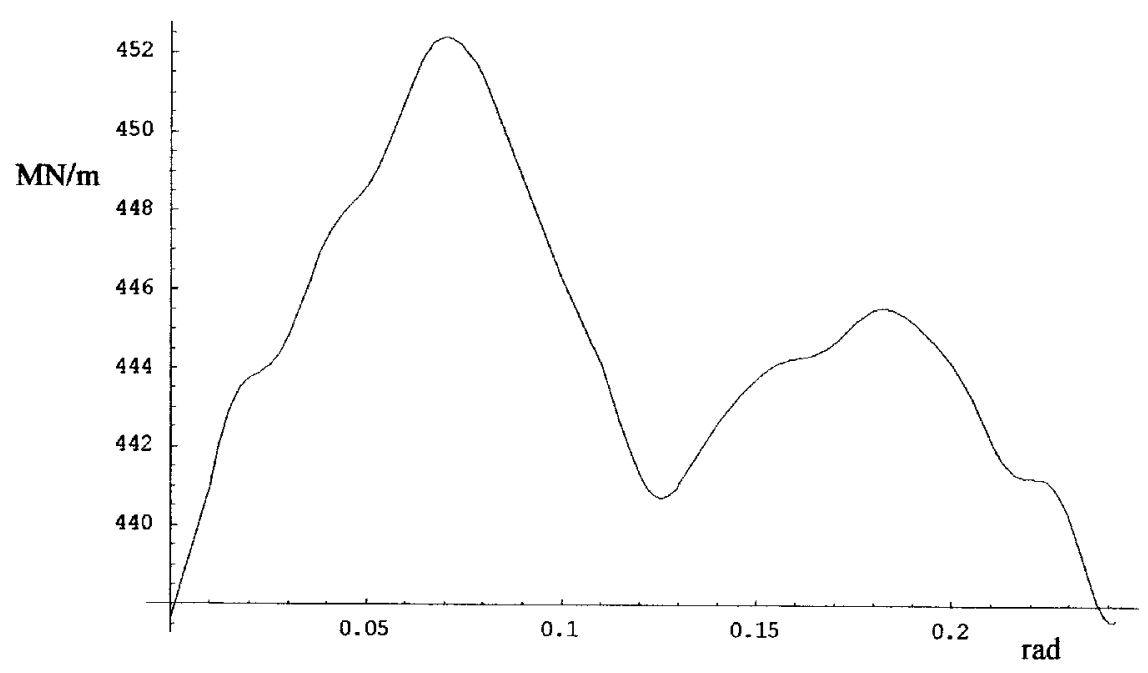

Fig. 4 Gear meshing stiffness variation with roll angle (second gear set-one cycle, unmodified gears) 


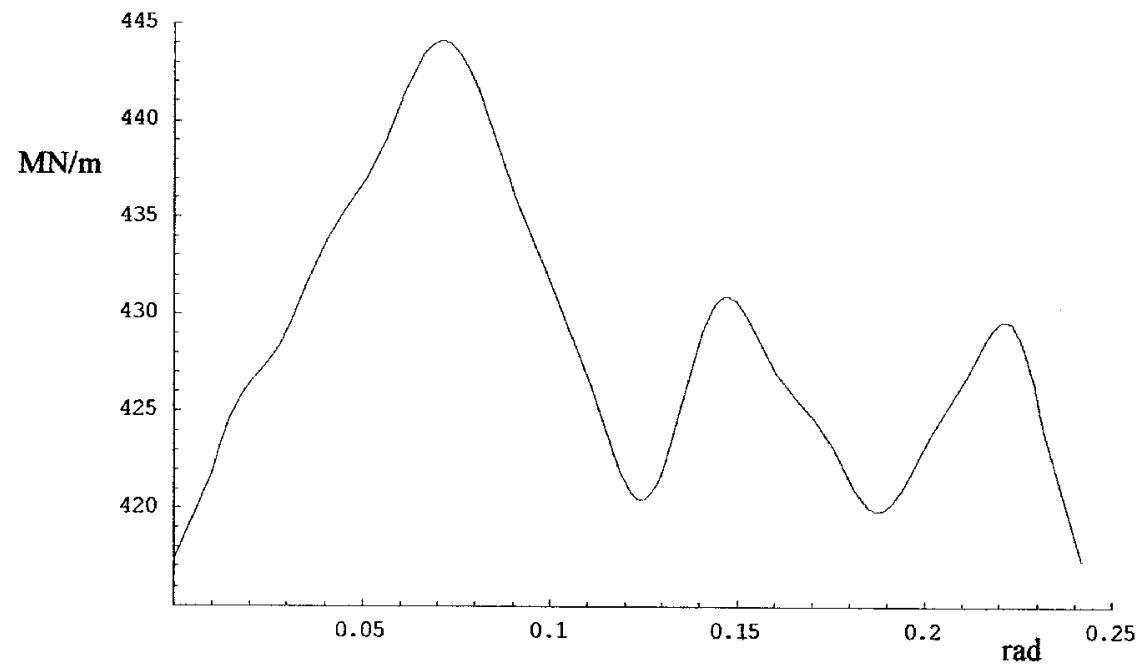

Fig. 5 Gear meshing stiffness variation with roll angle (second gear set-one cycle, modified gears)

of motion of such systems become strongly non-linear. Another important complication arises from the variable number of gear teeth pairs that are in contact at any one time, causing a variation in the equivalent gear meshing stiffness. These two factors introduce serious difficulties into the analysis and can obscure the interpretation of the numerical results. The dynamics of a gear pair system, involving backlash and time dependent mesh stiffness, $k(t)$, can be investigated by using piecewise-linear equations of motion with time dependent coefficients. In this analysis, the centres of both gears are restricted from lateral motion. The meshing stiffness depends on the number and position of the gear teeth pairs that are in contact at any given instance (Fig. 3) and is a periodic function of the relative angular position of the gears (Fig. 4). In the literature there are several studies on the meshing stiffness with respect to the roll angle [18-20]. Most of the models are based on FEA techniques for tooth compliance calculations, which in turn permit the computation of contact stiffness. In this study, an analysis of similar type has been followed, taking into account the profile deviations, tooth misalignments and crowning which induce significant changes in the form of the meshing cycle stiffness (Fig. 5) compared with that of the unmodified gear set (Fig. 4).
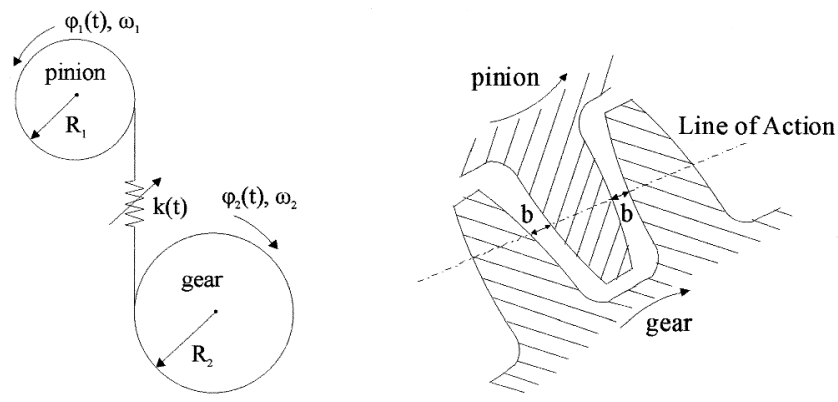

Fig. 6 Gear meshing teeth model
If variation from tooth to tooth (i.e. pitch errors, tooth finishing) are neglected, the fundamental frequency of both these quantities equals the gear meshing frequency

$$
\omega_{\mathrm{M}}=n_{1} \omega_{1}=n_{2} \omega_{2}
$$

The force developed between the pair of gears is given by the product $k(t) h(x)$, where

$$
x(t)=R_{1} \varphi_{1}(t)-R_{2} \varphi_{2}(t)
$$

and

$$
h(x)= \begin{cases}x-b, & x>b \\ 0, & |x|<b \\ x+b, & x<-b\end{cases}
$$

where $2 b$ represents the total normal backlash between the gear teeth. A model of gear meshing teeth is shown in Fig. 6 .

\subsection{Central bearing}

The centrepiece angular contact ball bearing is represented by the elastic model in Fig. 7 [21]. The total stiffness of each
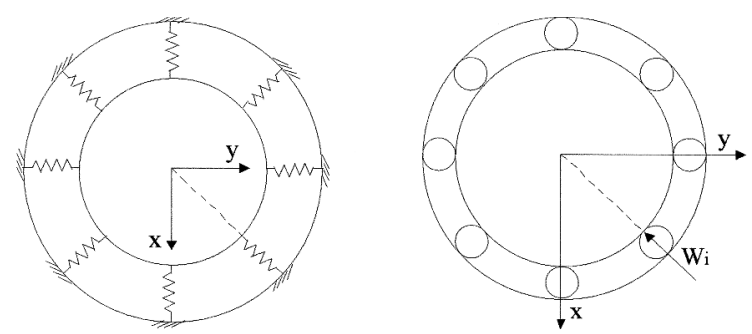

Fig. 7 Nonlinear bearing elastic model and restoring force considerations 


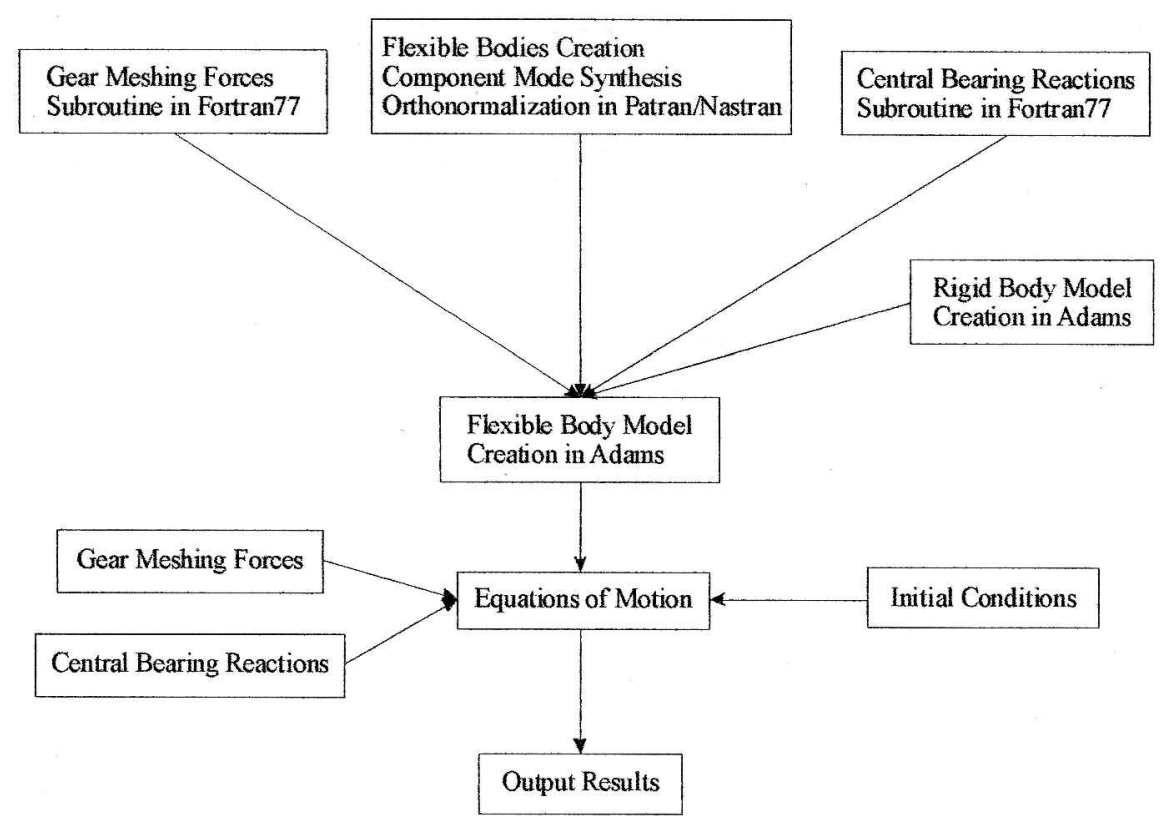

Fig. 8 Methodology — computational flow chart

ball in the radial direction owing to its interactions with the races is simulated by a non-linear rolling contact spring. The total restoring force at the point of contact of the $i$ th rolling element with the inner and outer raceways, according to the Hertzian theory, is expressed as

$$
W_{i}=K_{\mathrm{p}} \delta_{i}^{n}
$$

where $n=3 / 2$ for ball bearings and

$$
K_{\mathrm{p}}=\left[\frac{1}{\left(1 / K_{\mathrm{i}}\right)^{1 / n}+\left(1 / K_{\mathrm{o}}\right)^{1 / n}}\right]^{n}
$$

Taking into account the diameter of the ball $(7.144 \mathrm{~mm})$, the total number of 14 balls in the bearing, the pitch diameter of the bearing $(41 \mathrm{~mm})$ and the inner and outer groove radii ( $3.7 \mathrm{~mm}$ for both), the constant of proportionality $K_{\mathrm{p}}$ is finally calculated as $9.2 \times 10^{9} \mathrm{~N} / \mathrm{m}^{3 / 2}$.

The flow chart of the proposed overall methodology and computations is shown in Fig. 8, taking into account the different pieces of software used.

\section{PARAMETRIC SIMULATION STUDIES-DISCUSSION}

Parametric studies of sudden torque application are carried out with this flexible multi-body dynamics model of the drivetrain system under similar conditions to the experimental

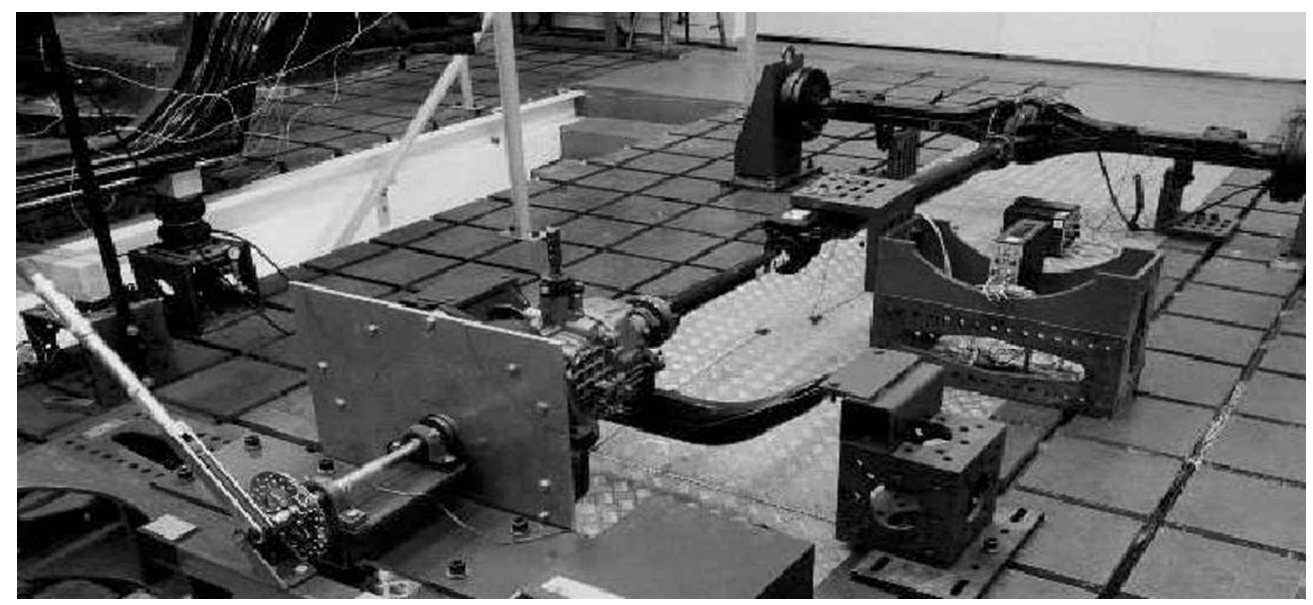

Fig. 9 Two-piece driveline experimental rig 

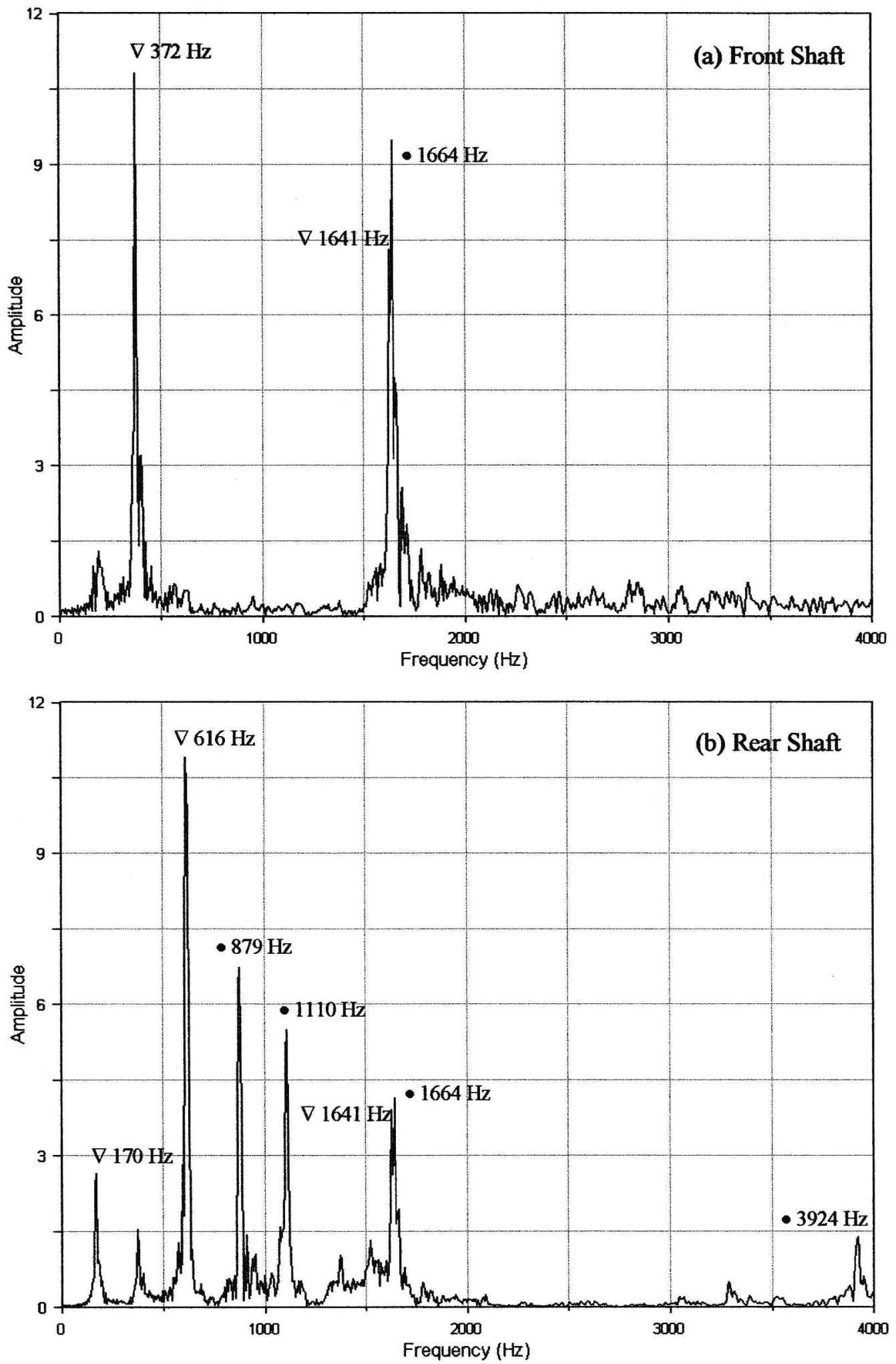

Fig. 10 FFT spectra of bending $(a, b)$ and torsional $(c, d)$ time history responses of the front and rear driveshafts corresponding to the central case: $\bullet$, breathing mode shape; $\bullet$ torsional mode shape; $\nabla$, bending mode shapes 

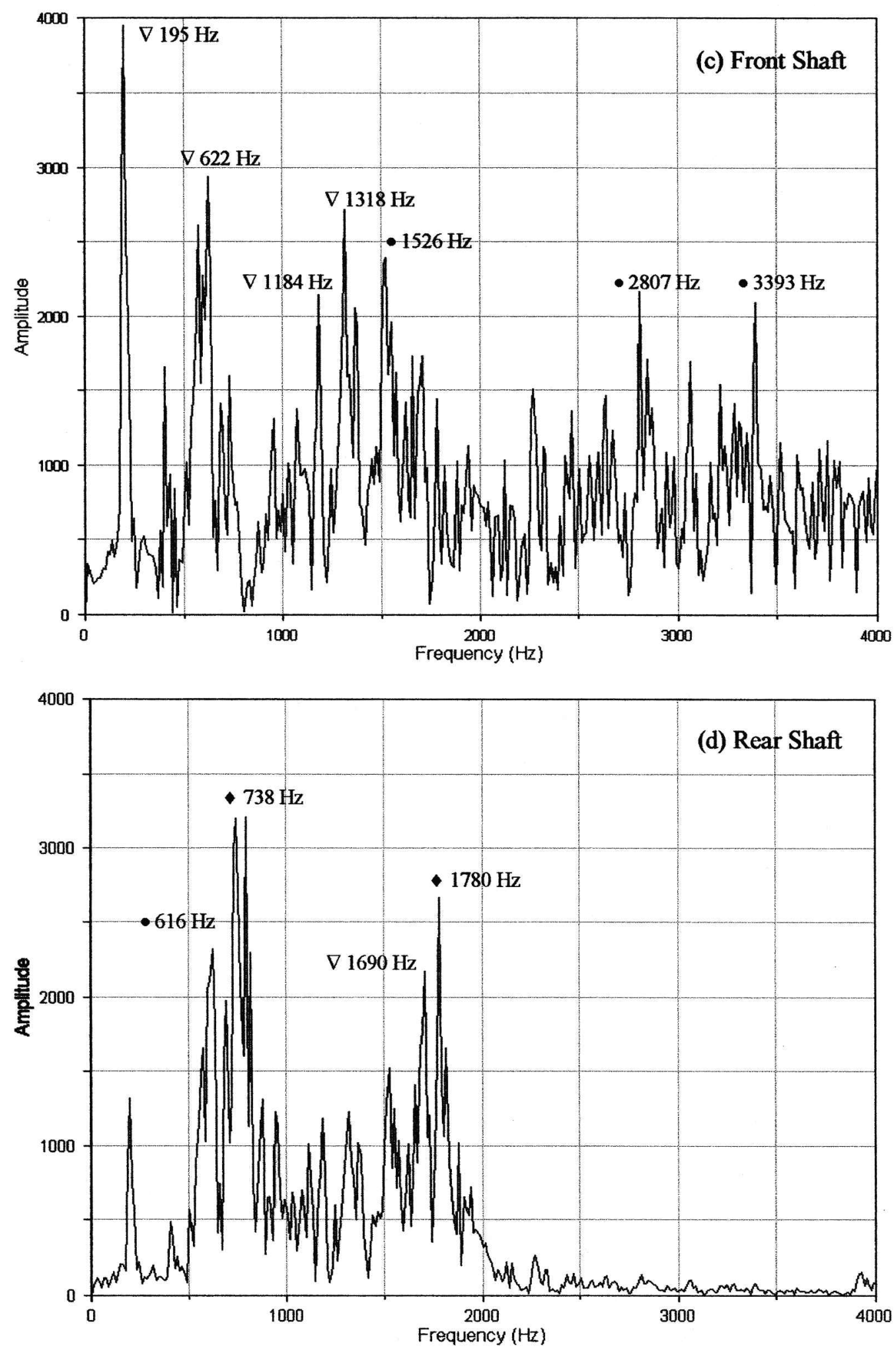

Fig. 10 (Continued) 
rig in reference [4]. The CPU time was approximately $1.5 \mathrm{~h}$ on a $1.8 \mathrm{GHz}$ Pentium IV desktop for $350 \mathrm{~ms}$, in 70000 computation time intervals.

The aforementioned static (i.e. not rotating) experimental rig was initially devised and set up at Ford Motor Company as shown in Fig. 9, with all the drivetrain components from the flywheel to the rear wheels. The rear wheel assembly, excluding the tyres, was clamped by bedplates to the ground. The transmission bell housing and the differential were also suitably mounted onto the ground. A specified preload torque was applied to the system to take up all the lash elements and to compress the clutch disc springs fully. The preload torque was held on a low inertial disc brake. The stored energy was instantaneously released in the form of a ramp sawtooth pulse. The duration of the torsional pulse was varied between 80 and $140 \mathrm{~ms}$ as required, inducing a generated lash take-up of the order of 1-2 ms of sufficiently short period to excite the higher-frequency clonk modes. Accordingly, a similar sawtooth excitation is introduced into the multi-body model in a variety of durations in order to investigate the effect on the vibration spectra. In Figs 10a to d the fast Fourier transform (FFT) spectra of the time history obtained signal for the bending and torsional driveshaft motions are shown for the central case of the ADAMS simulation parametric studies (halfladen vehicle, $135 \mathrm{~ms}$ ramp torque duration with $145 \mathrm{~N} / \mathrm{m}$ magnitude, average gear normal backlash values and modified gear meshing stiffness). The highest energy contribution to bending motions comes from the combined bending modes of the front and rear driveshafts, as shown in Figs $10 \mathrm{a}$ and $\mathrm{b}$. The breathing modes contribute much less to the response compared with the pure bending modes. The opposite effect is observed in the torsional motion spectra (Figs $10 \mathrm{c}$ and d), where the torsional and breathing modes are clearly dominating the response of both driveshafts. In Figs 11a to d, the mode shapes of the main aforementioned bending, torsional and breathing linearized driveline normal modes are presented in a magnified graphical scale so that they can be easily identified. The aforementioned results are in close qualitative agreement with the observations made in reference [4]. Noise radiation is expected to be relatively mild in this case, since the breathing modes, which are usually the main source of structure-borne noise, do not have the strongest presence in the response. Consequently, the clonk phenomenon is not severe.

The domination of higher-frequency bending and breathing modes is the main effect observed in the following case examined with higher backlash values $(100 \mu \mathrm{m}$ in the fourth gear pair and $118 \mu \mathrm{m}$ in the second gear pair), smaller ramp torque duration $(70 \mathrm{~ms})$ and all other parameters being the same, as shown in the spectra of Figs 12a to d. This torque duration simulates much more closely the behaviour of an aggressive driver. By comparison with Figs 10a to d, it is possible to observe a shift in the main energy volume to the region of higher frequencies, which would be expected by virtue of the fact that shorter excitation times excite these

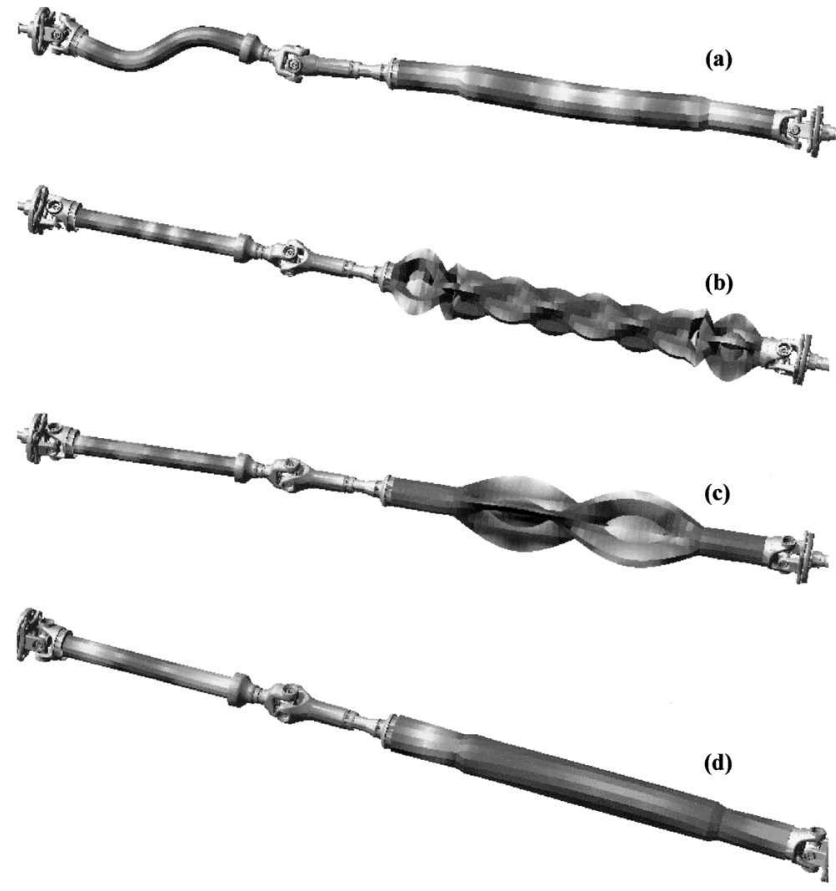

Fig. 11 Dominating mode shapes in magnified graphical scale corresponding to Fig. 10: (a) $1634 \mathrm{~Hz}$, bending mode; (b) $3389 \mathrm{~Hz}$, breathing mode; (c) $1664 \mathrm{~Hz}$, breathing mode; (d) $1731 \mathrm{~Hz}$, torsional mode

frequencies more effectively. In particular, in the torsional response spectra, the domination of breathing modes in terms of energy content corroborates the supposition that structure-borne noise is more prominent under the aforementioned conditions. Additionally, the results are in very close agreement with the response autoregression moving average spectra in reference [4]. The main contribution to clonk noise comes from the breathing mode shaped frequencies, higher than $3000 \mathrm{~Hz}$ for the front driveshaft and for frequencies in the region of $1650-1750 \mathrm{~Hz}$ for the rear driveshaft. These characteristic mode shapes are shown in the magnified graphical representations of Figs 13 a to d.

Other case studies reveal that lower backlash values ( $27 \mu \mathrm{m}$ in the fourth gear pair and $33 \mu \mathrm{m}$ in the second gear pair) adversely influence the domination of the breathing modes, particularly in the area of $3-4 \mathrm{kHz}$. Moreover, efforts to examine the effect on response spectra of unladen and fully laden vehicle conditions by modifying the driveline angles in the multi-body dynamics model did not reveal any marked differences. The reason for this is that a simulation of the non-rotating experimental rig (which cannot include the inertial effect of the different vehicle loading conditions) does not permit the introduction of the vehicle inertia mechanism into the multi-body model because it does not include different resistance levels in the driveline operation. Therefore, the severity of structural travelling waves with respect to vehicle loading cannot be observed. A new dynamic experimental rig that can simulate 

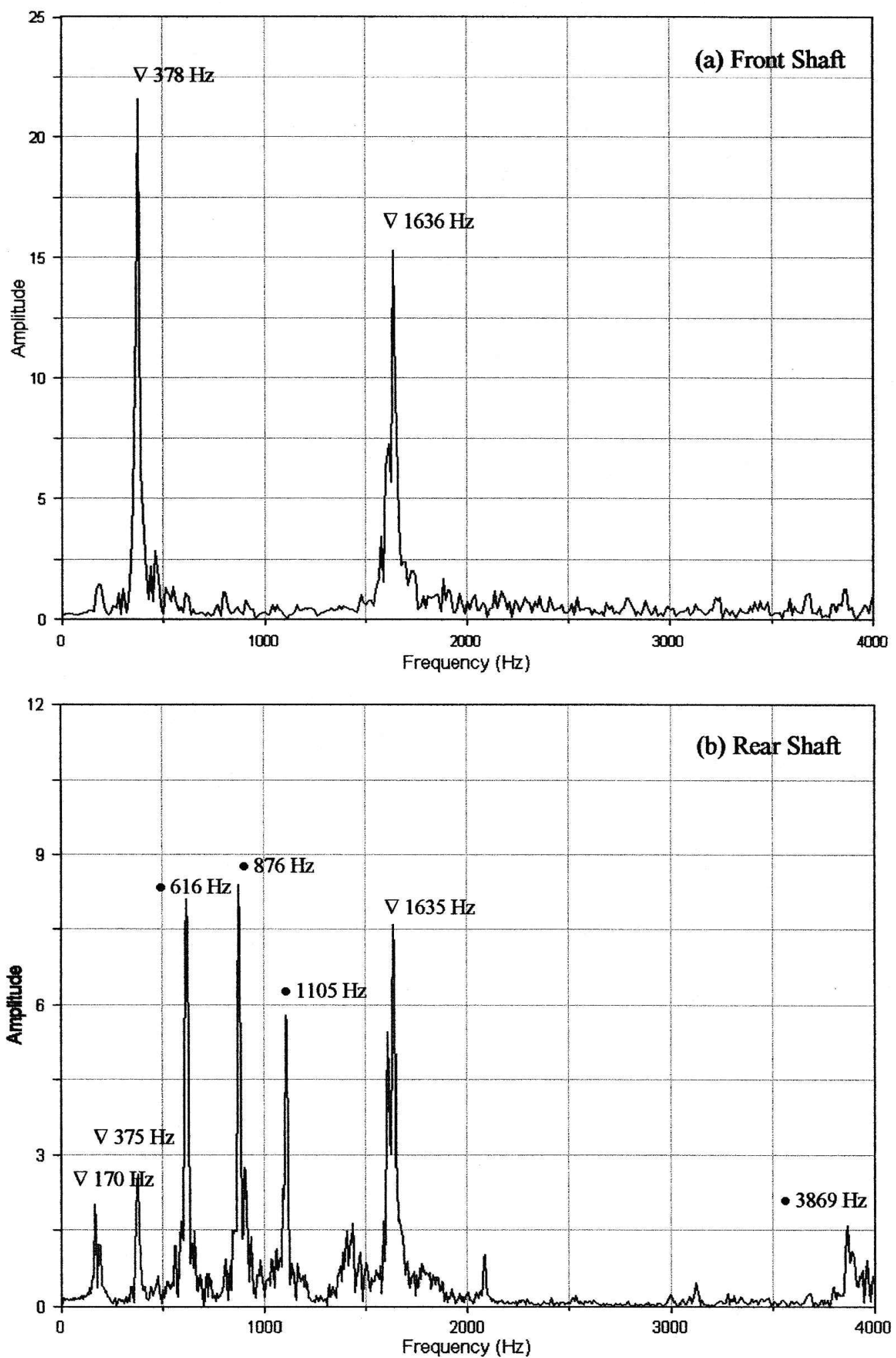

Fig. 12 FFT spectra of bending (a, b) and torsional (c, d) time history responses of the front and rear driveshafts for smaller ramp torque duration: •, breathing mode shape; $\bullet$ torsional mode shape; $\nabla$, bending mode shape 

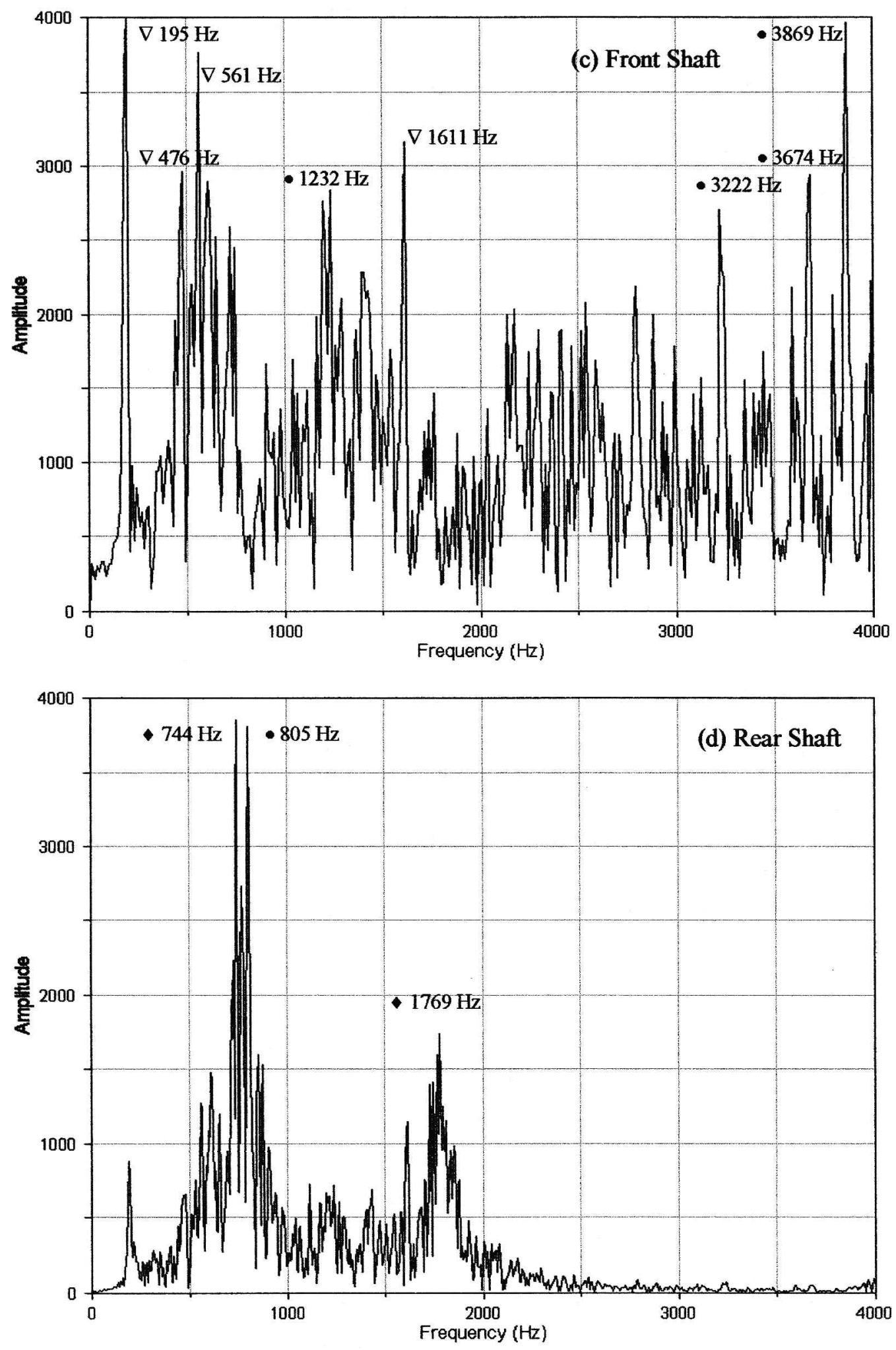

Fig. 12 (Continued) 


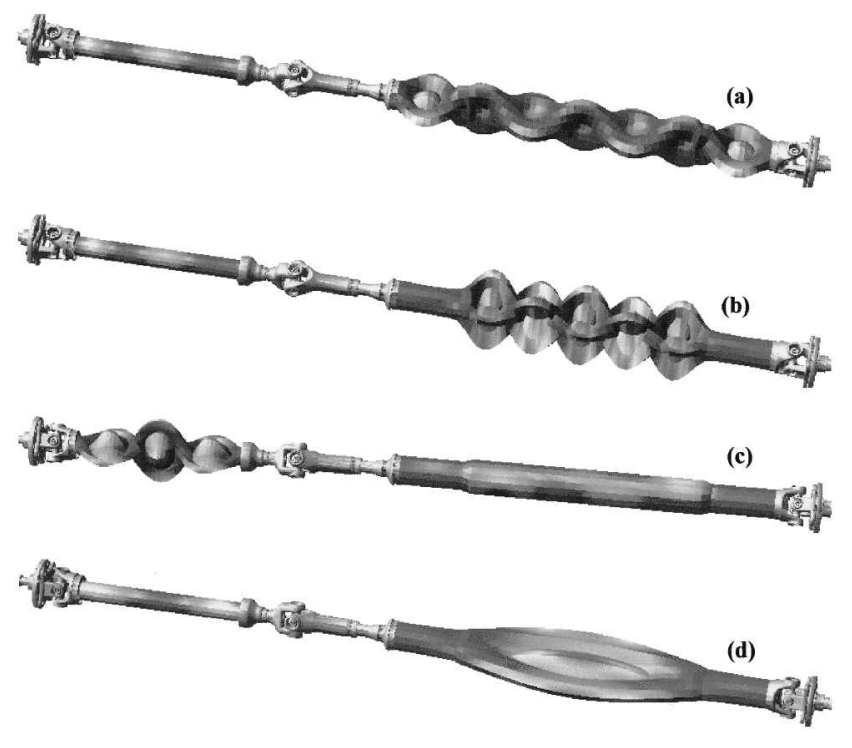

Fig. 13 Magnified graphical scale of dominating mode shapes corresponding to Fig. 12: (a) $3853 \mathrm{~Hz}$, breathing mode; (b) $3550 \mathrm{~Hz}$, breathing mode; (c) $3254 \mathrm{~Hz}$, breathing mode; (d) $617 \mathrm{~Hz}$, breathing mode

different in-service loading conditions is now being set up, including a three-piece driveline, and it is expected to shed some light on this aspect.

\section{ACKNOWLEDGEMENTS}

The authors wish to express their gratitude to Ford Motor Company, MSC Software and the Vehicle Foresight Directorate (EPSRC and DTI) for their sponsorship and financial support extended to this research project.

\section{REFERENCES}

1 Arrundale, D., Hussain, K., Rahnejat, H. and Menday, M.T. Acoustic response of driveline pieces under impacting loads (clonk). Proc. 31 st ISATA, 1998, 319-331.

2 Biermann, J.W. and Hagerodt, B. Investigation into the clonk phenomenon in vehicle transmission-measurement, modelling and simulation. Proc. Instn Mech. Engrs, Part K: J. Multibody Dynamics, 1999, 213(1), 53-60.

3 Menday, M., Rahnejat, H. and Ebrahimi, M. Clonk: an onomatopoeic response in torsional impact of automotive drivelines. Proc. Instn Mech. Engrs, Part D: J. Automobile Engineering, 1999, 213, 349-357.
4 Vafaei, S., Menday, M.T. and Rahnejat, H. Transient highfrequency elasto-acoustic response of a vehicular drivetrain to sudden throttle demand. Proc. Instn Mech. Engrs, Part K: J. Multi-body Dynamics, 2001, 215, 35-52.

5 Fothergil, D.J. and Swierstra, N. The application of nonlinear displacements modelling techniques to an automotive driveline for the investigation of shunt. VDI Ber., 1992, (1007), 163-179.

6 Hawthorn, J. A mathematical investigation of driveability. Instn Mech. Engrs, report C420/003, 1995.

7 Rooke, G., Chan, E.A. and Crossley, P.R. Computer modelling of a vehicle powertrain for driveability development. Institution of Mechanical Engineers Conference Transactions, 1995, C462/31/035, pp. 1-9.

8 Farshindiafar, A., Ebrahimi, M., Rahnejat, H. and Menday, M.T. High frequency torsional, vibration of vehicular driveline systems in clonk. Int. J. Veh. Des., 2002, 9, 127-149.

9 Krenz, R. Vehicle response to throttle tip in/tip out. SAE paper 850967, 1985.

10 Tobler, W. and Tsangerides, M. Dynamic behaviour of a torque converter with centrifugal bypass clutch. SAE paper $850461,1985$.

11 Petri, H. and Heldingfeld, D. The hydraulic torsion damper-a new concept for vibration damping in powertrains. SAE paper 892447, 1989.

12 Kelly, P., Menday, M., Rahnejat H. and Ebrahimi, M. Powertrain refinement: a combined experimental and multibody dynamics analysis approach. 8th Aachener Kolloquium, 1999.

13 Fahy, F.J. Sound and Structural Vibration: Radiation, Transmission and Response, 1985 (Academic Press, London).

14 Norton, M.P. Fundamentals of Noise and Vibration Analysis for Engineers, 1989 (Cambridge University Press).

15 Adams/Solver Reference Manual, Version 12.0, 2002 (Mechanical Dynamics Inc., Ann Arbor, Michigan).

16 Patran/Nastran Reference Manual, Version 2001, 1998 (MSC Software, Los Angeles, USA).

17 Craig Jr, R.R. Structural Dynamics-An Introduction to Computer Methods, 1981 (John Wiley, New York).

18 Zhang, J.J., Esat, I.I. and Shi, Y.H. Load analysis with varying mesh stiffness. Computers and Struct., 1999, 70, 273-280.

19 Choi, M. and David, J.W. Mesh stiffness and transmission error of spur and helical gears. SAE paper 901764, 1990.

20 Chen, Y.C. and Tsay, C.B. Stress analysis of helical gear set with localized bearing contact. Finite Elements in Analysis and Des., 2002, 38, 707-723.

21 Rahnejat, H. Influence of vibration on oil film in concentrated contacts. Doctoral thesis, Imperial College of Science and Technology, University of London, 1984. 